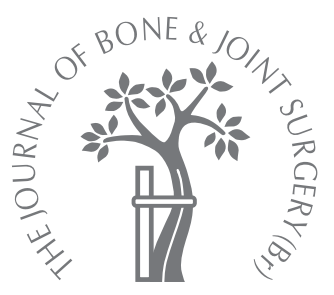

\title{
Fixator-assisted nailing and consecutive lengthening over an intramedullary nail for the correction of tibial deformity
}

\author{
F. E. Bilen, \\ M. Kocaoglu, \\ L. Eralp, \\ H. I. Balci \\ From Istanbul \\ Medical School, \\ Istanbul University, \\ Istanbul, Turkey
}

ㄷ. E. Bilen, MD, FEBOT, Orthopaedic Surgeon Department of Orthopaedic and Traumatology Acibadem Hospital Maslak, Buyukdere cd no: 40 , Maslak, Sariyer 34457 Istanbul, Turkey.

M. Kocaoglu, MD, Professor - L. Eralp, MD, Associate Professor

H. I. Balci, MD, Orthopaedic Resident

Department of Orthopaedics and Traumatology Istanbul Medical School, Istanbul University, Çapa, 34390 Istanbul, Turkey.

Correspondence should be sent to Dr F. E. Bilen;

e-mail: dr@erkalbilen.com

(C)2010 British Editorial Society of Bone and Joint Surgery doi:10.1302/0301-620X.92B1. $22637 \$ 2.00$

$J$ Bone Joint Surg $[\mathrm{Br}]$ 2010;92-B:146-52. Received 23 March 2009; Accepted after revision 4 August 2009

We report the results of using a combination of fixator-assisted nailing with lengthening over an intramedullary nail in patients with tibial deformity and shortening. Between 1997 and 2007,13 tibiae in nine patients with a mean age of 25.4 years (17 to 34 ) were treated with a unilateral external fixator for acute correction of deformity, followed by lengthening over an intramedullary nail with a circular external fixator applied at the same operating session. At the end of the distraction period locking screws were inserted through the intramedullary nail and the external fixator was removed.

The mean amount of lengthening was $5.9 \mathrm{~cm}$ (2 to 8). The mean time of external fixation was 90 days (38 to 265). The mean external fixation index was $15.8 \mathrm{days} / \mathrm{cm}(8.9$ to 33.1 ) and the mean bone healing index was 38 days/cm (30 to 60).

One patient developed an equinus deformity which responded to stretching and bracing. Another developed a drop foot due to a compartment syndrome, which was treated by fasciotomy. It recovered in three months. Two patients required bone grafting for poor callus formation.

We conclude that the combination of fixator-assisted nailing with lengthening over an intramedullary nail can reduce the overall external fixation time and prevent fractures and deformity of the regenerated bone.

We recently reported the combination of lengthening over an intramedullary nail ${ }^{1}$ and fixator-assisted nailing ${ }^{2}$ in the treatment of femoral shortening and deformity. ${ }^{3}$ In this study, we report our results using the combination of these techniques in the treatment of tibial shortening and deformity.

\section{Patients and Methods}

Between 1997 and 2007 we performed fixatorassisted correction of deformity and lengthening over an intramedullary nail during the same operating sessions in 13 tibiae of nine patients. This technique was not used in patients with open physeal plates and/or a history of infection, or with the diameter of the tibial medullary canal $<9 \mathrm{~mm}$. Three patients were female, and six were male. The mean age at the time of surgery was 25.4 years (17 to 34). Shortening was due to fibular hemimelia in three patients, poliomyelitis in two, and three had constitutional short stature with tibial deformity. The height of these three patients ranged from $140 \mathrm{~cm}$ to $159 \mathrm{~cm}$; and one of these also had a leg-length discrepancy of $2 \mathrm{~cm}$. One patient required surgery as a consequence of previous lengthening (Table I).
All patients were evaluated for malalignment and leg-length discrepancy using standing frontal and sagittal orthoroentgenograms. ${ }^{4-6}$ The deformities are recorded in Table I. The mean shortening was $6.75 \mathrm{~cm} \mathrm{(2} \mathrm{to} \mathrm{16),} \mathrm{and} \mathrm{the} \mathrm{mean}$ maximum angular deformity in the frontal or sagittal plane was $23^{\circ}\left(7^{\circ}\right.$ to $\left.58^{\circ}\right)$. The mechanical axis deviation was $-23 \mathrm{~mm}$ ( 2 to 35 ) in the six valgus tibiae (the valgus group) and $24 \mathrm{~mm}$ (17 to 35$)$ in the seven varus tibiae (the varus group). The mean medial proximal tibial angle was $96^{\circ}$ in the valgus group and $82^{\circ}$ in the varus group. The mean lateral distal tibial angle was $82^{\circ}$ in the valgus group and $86^{\circ}$ in the varus group. Four tibiae had pre-operative deformities in the sagittal plane, with a mean centre of rotation of angulation value of $30^{\circ}\left(12^{\circ}\right.$ to $\left.38^{\circ}\right)$. One tibia had an external rotation deformity of $15^{\circ}$. The centre of rotation of the sites of angulation ${ }^{4}$ were marked for each tibia, and the osteotomy levels planned accordingly. Using paper tracings, each procedure was simulated pre-operatively (Fig. 1) and planning included estimation of the diameter and length of the intramedullary nail to be used, as well as localisation of the interference (blocking) screws. Custom-made extra holes 
Table I. Demographic and outcome data on the study patients

\begin{tabular}{|c|c|c|c|c|c|c|c|c|c|c|c|c|c|c|c|c|c|c|c|}
\hline \multirow[b]{2}{*}{ Case } & \multirow[b]{2}{*}{ Gender } & \multirow[b]{2}{*}{$\begin{array}{l}\text { Age } \\
\text { (yrs) }\end{array}$} & \multirow[b]{2}{*}{ Tibia } & \multirow[b]{2}{*}{ Diagnosis } & \multicolumn{3}{|l|}{ Tibial } & \multirow[b]{2}{*}{$\begin{array}{l}\text { Number of } \\
\text { tibial } \\
\text { osteotomies }\end{array}$} & \multicolumn{3}{|c|}{ Pre-operative ${ }^{*}$} & \multicolumn{3}{|c|}{ Post-operative } & \multirow[b]{2}{*}{$\mathrm{EFT}^{\dagger}$} & \multirow[b]{2}{*}{$\begin{array}{l}\mathrm{EFl}^{\ddagger} \\
\text { (days/ } \\
\text { cm) }\end{array}$} & \multirow{2}{*}{$\begin{array}{l}\mathrm{BHI}^{\S} \\
\text { / (days } \\
\text { /cm) }\end{array}$} & \multirow{2}{*}{$\begin{array}{l}\text { Post- } \\
\text { operative } \\
\text { Paley } \\
\text { functional } \\
\text { score }\end{array}$} & \multirow[b]{2}{*}{$\begin{array}{l}\text { Complica- } \\
\text { tions }\end{array}$} \\
\hline & & & & & $\begin{array}{l}\text { Deformity } \\
\left({ }^{\circ}, \text { apex }\right)\end{array}$ & $\begin{array}{l}\text { Shorten- } \\
\text { ing (cm) }\end{array}$ & $\begin{array}{l}\text { Length- } \\
\text { ening } \\
\text { (cm) }\end{array}$ & & $\begin{array}{r}\text { MAD } \\
\text { s(mm }\end{array}$ & $\begin{array}{l}\text { MPT/ } \\
\text { (1) }\end{array}$ & $\begin{array}{l}\text { A LDTA } \\
\left({ }^{\circ}\right)\end{array}$ & $\begin{array}{l}\text { MAD } \\
\text { (mm) }\end{array}$ & $\begin{array}{l}\text { MPTA } \\
\left({ }^{\circ}\right)\end{array}$ & $\begin{array}{l}\text { LDTA } \\
\left({ }^{\circ}\right)\end{array}$ & & & & & \\
\hline 1 & $\mathrm{~F}$ & 17 & 1 & $\begin{array}{l}\text { Fibular } \\
\text { hemimelia }\end{array}$ & $\begin{array}{l}\text { 58, valgus } \\
\text { (multi- } \\
\text { apical) }\end{array}$ & 7 & 7 & 2 & -27 & 108 & 89 & 3 & 90 & 90 & 156 & 22,3 & 30 & $\begin{array}{l}80 \\
\text { (good) }\end{array}$ & $\begin{array}{l}\text { Poor callus } \\
\text { formation }\end{array}$ \\
\hline \multirow[t]{2}{*}{2} & $\mathrm{M}$ & 34 & 2 & $\begin{array}{l}\text { Sequel of } \\
\text { previous } \\
\text { lengthening }\end{array}$ & $\begin{array}{l}35, \text { ante- } \\
\text { curvation } \\
\text { and 5, } \\
\text { varus }\end{array}$ & - & 5 & 2 & 35 & 81 & 95 & 0 & 89 & 90 & 82 & 16,4 & 48 & $\begin{array}{l}95 \\
\text { (excellent) }\end{array}$ & None \\
\hline & & & 3 & $\begin{array}{l}\text { Sequel of } \\
\text { previous } \\
\text { lengthening }\end{array}$ & $\begin{array}{l}38, \text { ante- } \\
\text { curvation } \\
\text { and } 7, \\
\text { valgus }\end{array}$ & - & 5 & 2 & -17 & 94 & 89 & 0 & 90 & 90 & 82 & 16,4 & 48 & $\begin{array}{l}95 \\
\text { (excellent) }\end{array}$ & None \\
\hline 3 & $\mathrm{~F}$ & 32 & 4 & Polio sequel & $\begin{array}{l}10, \text { valgus } \\
\text { and } \\
2 \mathrm{~cm} \text {, } \\
\text { femoral } \\
\text { shortening }\end{array}$ & 4.5 & 6 & 1 & -35 & 98 & 87 & -3 & 87 & 91 & 100 & 16,6 & 30 & $\begin{array}{l}100 \\
\text { (excellent) }\end{array}$ & $\begin{array}{l}\text { Equinus } \\
\text { contracture }\end{array}$ \\
\hline 4 & $\mathrm{M}$ & 28 & 5 & Polio sequel & $\begin{array}{l}15 \text {, exter- } \\
\text { nal } \\
\text { rotation } \\
\text { and } \\
10, \text { valgus }\end{array}$ & 4 & 4 & 1 & 2 & 91 & 90 & 1 & 90 & 90 & 60 & 20 & 60 & $\begin{array}{l}95 \\
\text { (excellent) }\end{array}$ & None \\
\hline \multirow[t]{2}{*}{5} & $\mathrm{M}$ & 26 & 6 & $\begin{array}{l}\text { Constitu- } \\
\text { tional } \\
\text { short } \\
\text { stature }\end{array}$ & $\begin{array}{l}10, \text { genu } \\
\text { varum, } \\
\text { and } 7, \\
\text { ankle } \\
\text { valgus }\end{array}$ & 2 & 4 & 1 & 27 & 82 & 78 & 6 & 90 & 85 & 38 & 9,5 & 38 & $\begin{array}{l}100 \\
\text { (excellent) }\end{array}$ & None \\
\hline & & & 7 & $\begin{array}{l}\text { Pre- } \\
\text { operative } \\
156 \mathrm{~cm}\end{array}$ & $\begin{array}{l}12, \text { genu } \\
\text { varum, } \\
\text { and } 10 \\
\text { ankle } \\
\text { valgus }\end{array}$ & - & 2 & 1 & 17 & 83 & 84 & 4 & 90 & 86 & 38 & 19 & 38 & $\begin{array}{l}100 \\
\text { (excellent) }\end{array}$ & None \\
\hline 6 & $\mathrm{M}$ & 28 & 8 & $\begin{array}{l}\text { Fibular } \\
\text { hemimelia }\end{array}$ & $\begin{array}{l}45, \text { valgus } \\
\text { and } \\
35 \text {, ante- } \\
\text { curvation }\end{array}$ & 7 & 7,3 & 1 & -27 & 80 & 70 & 0 & 89 & 90 & 105 & 17,5 & 30 & $\begin{array}{l}100 \\
\text { (excellent) }\end{array}$ & None \\
\hline 7 & $M$ & 17 & 9 & $\begin{array}{l}\text { Fibular } \\
\text { hemimelia }\end{array}$ & $\begin{array}{l}45, \text { valgus } \\
\text { and } 12, \\
\text { antecurva- } \\
\text { tion }\end{array}$ & 16 & 8 & 3 & -34 & 105 & 65 & 6 & 90 & 90 & 265 & 33,1 & 45 & $\begin{array}{l}80 \\
\text { (good) }\end{array}$ & $\begin{array}{l}\text { Poor callus } \\
\text { formation }\end{array}$ \\
\hline \multirow[t]{2}{*}{8} & $M$ & 22 & 10 & $\begin{array}{l}\text { Constitu- } \\
\text { tional } \\
\text { short } \\
\text { stature }\end{array}$ & $\begin{array}{l}7, \text { genu } \\
\text { varum }\end{array}$ & - & 7 & 1 & 23 & 83 & 85 & 0 & 91 & 90 & 62 & 8,9 & 30 & $\begin{array}{l}100 \\
\text { (excellent) }\end{array}$ & None \\
\hline & & & 11 & $\begin{array}{l}\text { Pre- } \\
\text { operative } \\
159 \mathrm{~cm}\end{array}$ & $\begin{array}{l}7, \text { genu } \\
\text { varum }\end{array}$ & - & 7 & 1 & 23 & 83 & 86 & 0 & 92 & 90 & 62 & 8,9 & 30 & $\begin{array}{l}95 \\
\text { (excellent) }\end{array}$ & $\begin{array}{l}\text { Compart- } \\
\text { ment } \\
\text { syndrome } \\
\text { related } \\
\text { drop foot }\end{array}$ \\
\hline \multirow[t]{2}{*}{9} & $\mathrm{~F}$ & 25 & 12 & $\begin{array}{l}\text { Constitu- } \\
\text { tional } \\
\text { short } \\
\text { stature }\end{array}$ & $\begin{array}{l}8, \text { genu } \\
\text { varum }\end{array}$ & - & 7 & 1 & 21 & 82 & 86 & 4 & 89 & 89 & 60 & 8,6 & 35 & $\begin{array}{l}100 \\
\text { (excellent) }\end{array}$ & None \\
\hline & & & 13 & $\begin{array}{l}\text { Pre- } \\
\text { operative } \\
140 \mathrm{~cm}\end{array}$ & $\begin{array}{l}8, \text { genu } \\
\text { varum }\end{array}$ & - & 7 & 1 & 21 & 82 & 86 & 4 & 88 & 89 & 60 & 8,6 & 35 & $\begin{array}{l}100 \\
\text { (excellent) }\end{array}$ & None \\
\hline
\end{tabular}

* MAD, mechanical axis deviation; MPTA, medial proximal tibial angle; LDTA, lateral distal tibial angle

$\dagger$ EFT, external fixation time

¥ EFI, external fixation index

$\S \mathrm{BHI}$, bone healing index

for locking screws were made in the nails if necessary. Unilateral fixators (Hex-Fix system, Smith \& Nephew, Memphis, Tennessee), and intramedullary nails (Ortopro Tibial Nail 4G, Istanbul, Turkey) were used for correction of defor- mity and circular external fixators (Tasarim Med, Istanbul, Turkey) for lengthening. Lengthening and deformity were corrected by a one-level osteotomy in nine tibiae. Osteotomies at two levels were performed in three, and at three levels in one. 


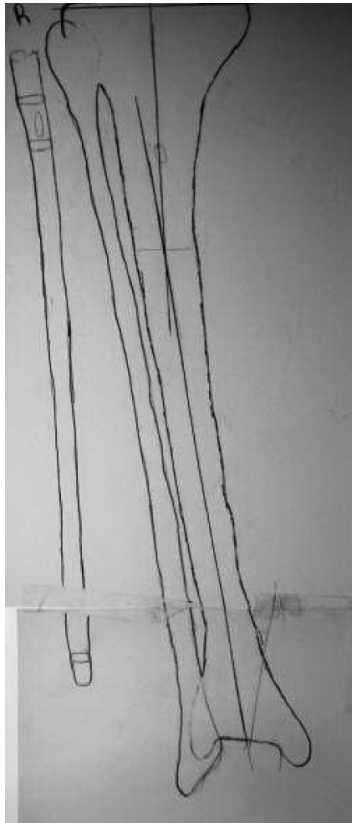

Fig. 1a

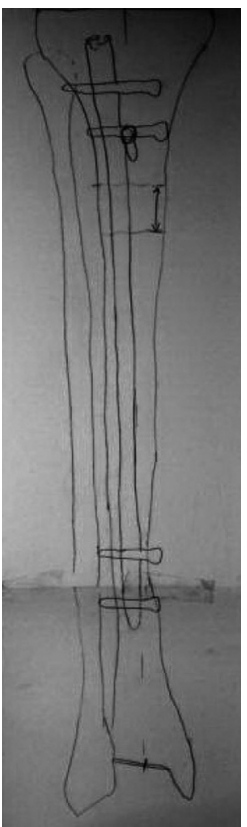

Fig. 1b
Paper tracing for pre-operative planning a) pre-operative (centre of rotation of angulation locations and estimated size of the intramedullary nail drawn). b) Post-operative (lengthening included).

The evaluation criteria included the bone healing index (BHI), which represents the duration of consolidation in days per cm length gained, the external fixation index, which represents the duration of external fixation in days per $\mathrm{cm}$ length gained, ${ }^{7}$ and measurements of post-operative alignment.

Consolidation was considered complete when three of four cortices of regenerated bone were intact on the anteroposterior and lateral radiographs. Outcome was assessed using Paley's functional score, ${ }^{8}$ and complications were classified according to his system. ${ }^{9}$

Operative technique. The patients were placed supine on a radiolucent table and evaluated from hip to ankle with a $\mathrm{C}$ arm image intensifier in both the frontal and sagittal planes prior to sterile preparation. Schanz screws were inserted parallel to the proximal and distal joint lines, with care taken to stay in the posterior part of the tibia to leave enough room for insertion of the intramedullary nail. In order to correct and/or maintain the rotational alignment of the tibia the proximal screws were inserted horizontally once a true lateral view of the knee was obtained using the image intensifer. The distal Schanz screws were inserted horizontally once a true lateral view of the ankle was obtained in the same way. All screws must be in line in the sagittal plane in order to prevent deformity. Osteotomies were performed either by the multiple drill hole technique or with a Gigli saw at the level of each centre of rotation of angulation. The level of the lengthening osteotomy and the length of the intramedullary

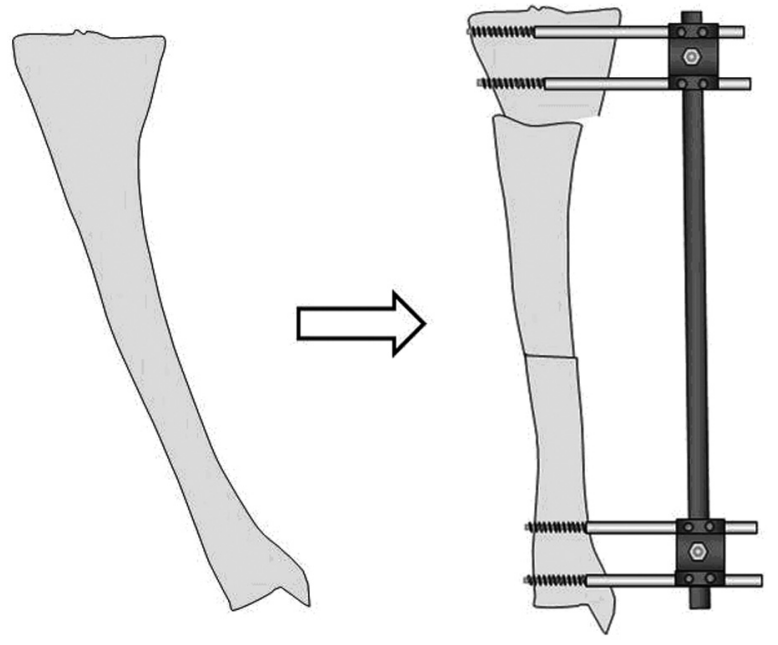

Fig. $2 a$

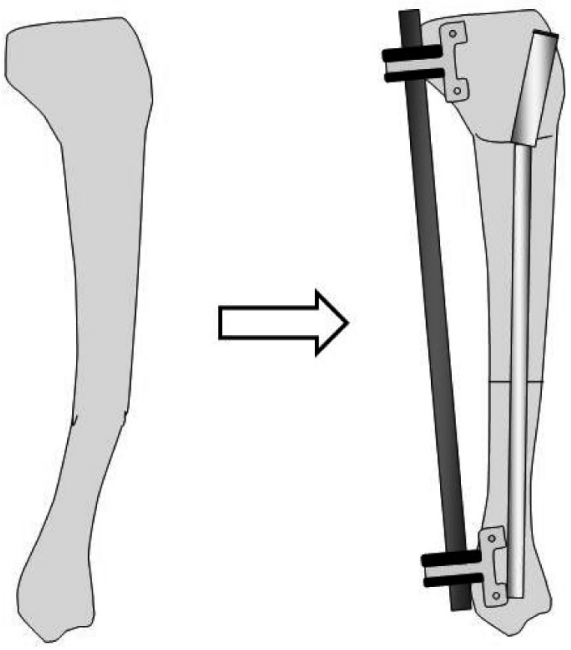

Fig. 2b

Schematic drawing of a tibia with deformity a) anteroposterior and b) lateral views before and after the fixator-assisted correction of the deformity through two osteotomies.

nail were selected to ensure that at least $6 \mathrm{~cm}$ of the nail were above the distraction gap at the end of the lengthening. The fibula was osteotomised at the mid-diaphyseal level through a small incision, and the deformity corrected acutely using a Hex-Fix unilateral external fixator (Fig. 2). At this point, intra-operative radiographs of the tibia were taken in both planes, and the malalignment tested. If the desired correction had not been achieved, the external fixator was readjusted and additional radiographs were taken. Once satisfactory correction was achieved, interference screws were inserted in the frontal and/or sagittal plane in order to maintain the necessary amount of translation and to narrow the medullary canal, especially in the metaphyseal area (Fig. 3). A small transverse incision was made over the patellar ligament, and an intramedullary guide was inserted using a patellar ligament splitting approach under fluoroscopic control. The 


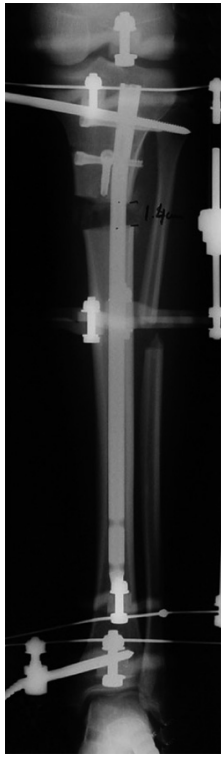

Fig. 3

Radiograph of a right tibia in the lengthening phase. A blocking screw in the proximal fragment prevents loss of angular correction during lengthening. Proximal and distal tibiofibular joints are secured to prevent dislocation by a retrograde Schanz screw proximally and an olive Kirschner-wire distally.

medullary canal was over-reamed by $1.5 \mathrm{~mm}$ more than the diameter of the intramedullary nail to be used in order to allow sliding of the nail for lengthening. The nail was then inserted and locked proximally (Fig. 4), and the unilateral external fixator was exchanged for a circular external fixator consisting of three rings (Fig. 5). The middle ring adds stability, but is not used for fixation. In order to prevent dislocation of the tibiofibular joints during lengthening, a Schanz screw was used proximally to secure the fibula to the tibia, with purchase only on the medial cortex to prevent discomfort and skin problems, and an olive Kirschner (K)-wire was used distally (Fig. 3). Using an image intensifier, all Schanz screws and K-wires were checked to ensure that they were not in contact with the intramedullary nail, and a distraction test performed using the external fixator to check distraction at the level of the osteotomy for lengthening.

On the day of the operation, isometric quadriceps and range of movement exercises for the knee were started. On the first post-operative day, weight-bearing with two crutches was allowed. The patients gradually discarded their crutches or sticks during the first month after the procedure. Distraction was initiated seven days post-operatively at a rate of $0.25 \mathrm{~mm}$, four times per day. During lengthening, radiographs were taken every two weeks to monitor the progress of distraction, and the patient was assessed clinically.

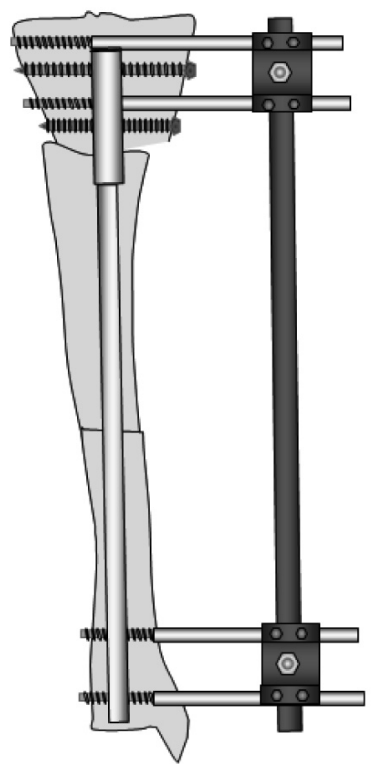

Fig. 4

Schematic drawing showing the intramedullary nail locked proximally but not distally to permit sliding for lengthening.

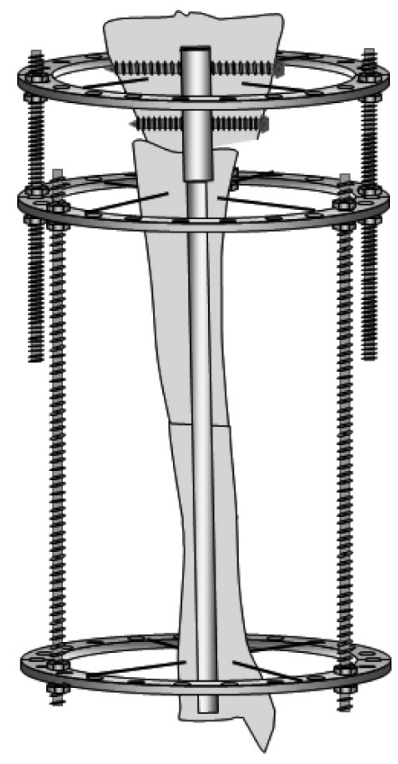

Fig. 5

Schematic drawing showing the unilateral external fixator exchanged for a circular fixator consisting of three rings.

When the desired amount of lengthening was achieved distal interlocking screws were inserted and the circular external fixator removed (Fig. 6). Full weight-bearing was not allowed until radiological consolidation was estab- 


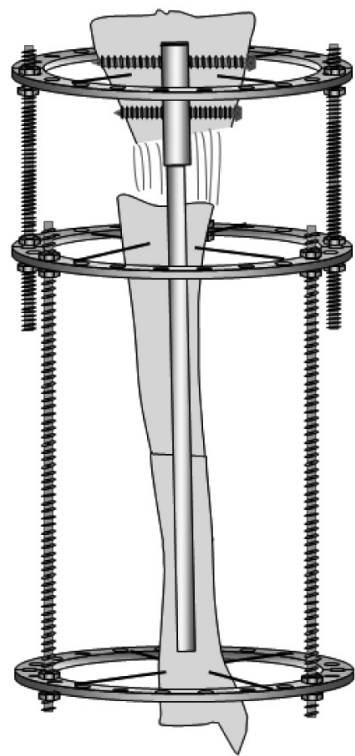

Fig. $6 a$

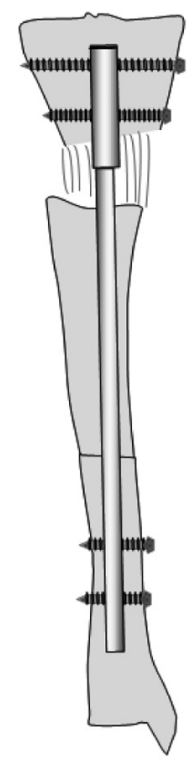

Fig. $6 b$
Schematic drawing showing that when the desired lengthening has been achieved a) the intramedullary nail is locked distally and b) the external fixator is removed.

lished. Radiographs from one patient (Fig. 7) demonstrate the steps of treatment.

Informed consent was obtained from each patient prior to treatment.

\section{Results}

The mean follow-up time was for 35 months (14 to 22). The mean lengthening was $5.9 \mathrm{~cm}(2$ to 8$)$. The mean mechanical axis deviation for the lower extremity improved to $1.2 \mathrm{~mm} \mathrm{(-3} \mathrm{to} \mathrm{6)} \mathrm{in} \mathrm{the} \mathrm{valgus} \mathrm{group} \mathrm{(pre-}$ operative mean, $-23 \mathrm{~mm}$ and $2.6 \mathrm{~mm}(0$ to 6$)$ in the varus group (pre-operative mean, $24 \mathrm{~mm}$ ). One patient with femoral shortening of $2 \mathrm{~cm}$ was overlengthened by $1.5 \mathrm{~cm}$ to reduce the amount of leg-length discrepancy. Delayed consolidation was seen in two patients. There were no cases of premature consolidation. The mean duration of external fixation was 90 days (38 to 265). The mean external fixation index was 15.8 days/cm (8.9 to 33.1). The mean BHI was 38 days/cm (30 to 60 ). The mean post-operative value of the medial proximal tibial angle was $89^{\circ}$ in the valgus group and $90^{\circ}$ in the varus group. The mean post-operative value of the lateral distal tibial angle was $90^{\circ}\left(90^{\circ}\right.$ to $\left.91^{\circ}\right)$ in the valgus group and $88^{\circ}\left(85^{\circ}\right.$ to $\left.90^{\circ}\right)$ in the varus group. There were no residual sagittal or rotational deformities in any tibia post-operatively.

Paley's functional score ${ }^{8}$ was excellent in seven patients and good in the remaining two. There were four complications, including one problem, three obstacles and no sequelae, as categorised according to Paley's classification. ${ }^{9}$ One patient developed an equinus contracture which responded to bracing and stretching. Two patients had poor callus formation and subsequently underwent grafting with demineralised bone matrix. One patient developed a drop foot due to a compartment syndrome, which was treated by fasciotomy and resolved three months after the procedure. There were no infections.

\section{Discussion}

For several years, circular external fixators have been the method of choice for correction of shortening and deformity in the long bones. ${ }^{10}$ Besides bone lengthening, circular external fixators also allow post-operative angular and rotational adjustments. However, a major disadvantage is that the patient must have the fixator on during both the lengthening and the consolidation phases. This can result in problems such as pin-track infection, discomfort, and joint stiffness. ${ }^{1,10,11}$

Shortening and deformity can recur or develop secondary to iatrogenic deformities following removal of the fixator at the end of the consolidation phase, especially in patients with metabolic bone disease. ${ }^{12}$

By combining the techniques of fixator-assisted nailing and lengthening over an intramedullary nail for the treatment of tibial deformities associated with leg-length discrepancy, the drawbacks associated with circular external fixators can be considerably reduced and the advantages of intramedullary fixation gained., ${ }^{1,13-15}$ The addition of intramedullary nailing to the circular fixator technique alone reduces the external fixation time and index, as well as the number of $\mathrm{K}$-wires and Schanz pins needed for stable fixation. Furthermore, loss of correction, progressive recurrence of deformity, and regenerate bone fracture are prevented by the intramedullary nail. ${ }^{1-3}$ However, the combined techniques require careful analysis of the deformity and pre-operative preparation. A medullary canal of at least $9 \mathrm{~mm}$ in diaphyseal diameter is necessary in order to use this technique. The surgeon must be familiar with external fixation and intramedullary nailing, as both have a steep learning curve. The acute correction of the tibial deformity with the unilateral fixator is technically demanding and may cause secondary rotational and/or sagittal deformity if not applied correctly. Accurate placement of the Schanz screws is crucial and may lead to prolonged use of the image intensifier early in the learning curve. By contrast to the technique of femoral fixatorassisted nailing/lengthening over an intramedullary nail, a circular external fixator is preferred in the tibial method so as to prevent valgus deviation, which can occur when unilateral fixators are used for tibial lengthening. ${ }^{1,12}$

Donnan et $\mathrm{al}^{7}$ reported acute correction of lower limb deformity and simultaneous lengthening with a monolateral fixator. Their series consisted mainly of children, and they used the technique both in the tibia and the femur. In their series the median external fixation index in the tibial subgroup, which was equivalent to the BHI as a monolateral fixator only was used, was 37.3 days $/ \mathrm{cm}$. In 


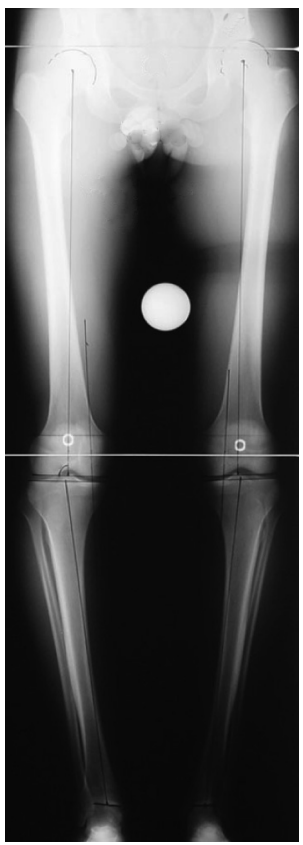

Fig. 7a

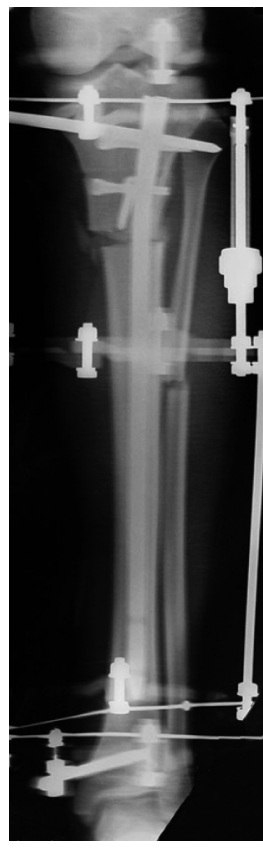

Fig. $7 b$

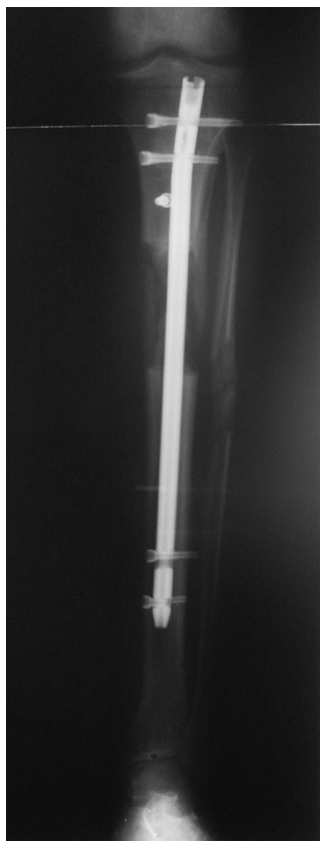

Fig. 7c

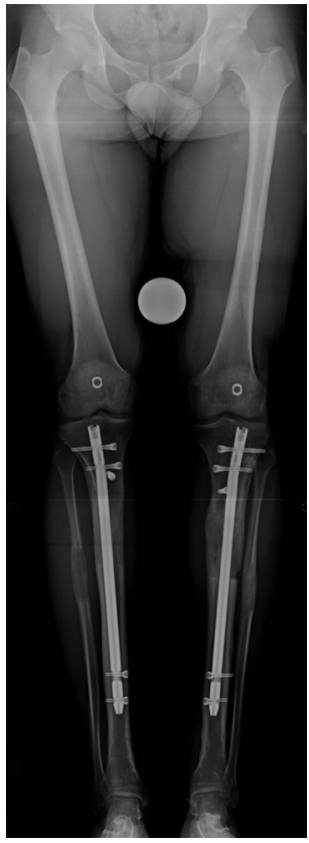

Fig. 7d

Radiographs of a patient showing the major steps of the procedure. a) Pre-operative standing orthoroentgenogram, b) the corrective osteotomy; intramedullary nail locked only proximally, circular ex-fix applied for lengthening, c) the distraction phase finished; nail locked distally as well proximally and the ex-fix removed and d) standing orthoroentgenogram at the end of the treatment.

this series, the median external fixation index was significantly lower (16.4 days/cm), but the median BHI was similar (35 days/cm).

Park et $\mathrm{al}^{16}$ compared the results of tibial lengthening over an intramedullary nail with use of the conventional circular external fixator for idiopathic short stature and concluded that tibial lengthening over an intramedullary nail resulted in new bone formation equal to that obtained with the former, but reduced the external fixator index and the rate of complications. In another study of tibial lengthening over an intramedullary nail, Watanabe et al, ${ }^{17}$ reported a mean external fixation index of 18 days $/ \mathrm{cm}$, which is similar to our results. Their mean consolidation index of 45.1 days $/ \mathrm{cm}$ (BHI) was also similar to ours (38 days $/ \mathrm{cm})$.

Tsuchiya et $\mathrm{al}^{10}$ reported correction of deformity followed by lengthening using the Ilizarov method to treat deformity and shortening in the lower limb. The mean external fixation index (equal to BHI) in the tibial subgroup was 55.9 days $/ \mathrm{cm}$.

In this study only one patient developed an equinus contracture at the end of the consolidation phase. It responded to stretching and bracing. We attribute this to the short external fixation time, and to early aggressive physiotherapy which is possible with the additional stability provided by the intramedullary nail.

Another alternative for the treatment of patients with deformity and shortening in the same segment of the limb is a fully implantable lengthening nail. Baumgart et al ${ }^{18}$ reported satisfactory results in a patient with Ollier's disease using a fully implantable lengthening nail (Fitbone). This technique eliminates the need for an external fixator and is more comfortable. This device is currently limited to lengthening up to $6 \mathrm{~cm}$. In our series, seven of 13 tibiae were lengthened more than $6 \mathrm{~cm}$. The method does not permit weight-bearing when used bilaterally, and the cost at present is about three times greater than that of fixator-assisted nailing/lengthening over an intramedullary nail.

Various other techniques have been described to reduce external fixation time during lengthening procedures. Wu and Chen ${ }^{19}$ reported their results for lengthening using a circular external fixator and secondary internal fixation. They used a Hoffman fixator and intramedullary nails, plating, or rush pins for internal fixation. The median external fixator index was 12 days $/ \mathrm{cm}$ (the median external fixation time was 1.8 months; the median amount of lengthening was $4.5 \mathrm{~cm}$ ). The median BHI was 45 days $/ \mathrm{cm}$. These results were similar to those obtained in this study, with a median external fixation index of 16.4 days $/ \mathrm{cm}$, and a median BHI of 35 days $/ \mathrm{cm}$.

Rozbruch et $\mathrm{al}^{20}$ reported a case-matched comparison of their results for limb lengthening using a circular external fixator followed by intramedullary nailing compared to the classic method. The mean external fixation index in their seies was 15 days/cm and the mean BHI was 24 days $/ \mathrm{cm}$. They attributed the reduction in the BHI to the enhancement of bone healing by reaming, a phenomenon that could be compared to exchange nailing for nonunion of the tibia and femur. Another advantage of this technique is that a fulllength, large-diameter intramedullary nail can be used, as opposed to the lengthening over an intramedullary nail in 
which a smaller-diameter nail must be used to allow sliding. As the nail is inserted prior to lengthening, it will be relatively shorter at the end of the procedure. Rozbruch et $\mathrm{al}^{20}$ reported no difference in the rate of infection between the two groups; however, there is concern regarding deep infection when immediate nailing is performed just after removal of a circular external fixator. ${ }^{19,21,22}$

Park et $\mathrm{al}^{16}$ reported a significantly lower complication rate in lengthening over an intramedullary nail compared to a circular external fixator (1.23 versus 2.56 per tibia). On the other hand, Kristiansen and Steen ${ }^{23}$ reported a high rate of serious complications in patients treated with tibial lengthening over an intramedullary nail, leading them to abandon the technique. In our series tibial fixator-assisted nailing/lengthening over an intramedullary nailing was associated with few complications, namely one problem, three obstacles and no sequelae.

None of our patients had a fat embolism. We attribute the lack of this complication to the fact that the osteotomies were performed prior to intramedullary nailing. Patients who underwent surgical reconstruction of more than one bone segment at the same time received a blood transfusion. We believe that the increased blood loss is related more to the increased number of osteotomies than to the use of intramedullary nailing. We were careful to ensure that there was no contact between the nail and the external fixation pins, as described by Herzenberg and Paley. ${ }^{1}$ None of our patients developed an intramedullary infection related to the Schanz screws.

Lengthening of the long bones, especially if associated with immediate correction of angular deformity, can be associated with neurovascular compromise. ${ }^{11,13,24}$ There is an increased risk of damage to the peroneal nerve when acute correction of a valgus knee is carried out. In order to avoid this, either prophylactic release of the nerve or a closing wedge osteotomy can be performed. The latter is associated with loss of length and should be avoided if possible when lengthening is needed. Prophylactic release of the peroneal nerve is advised for acute correction of valgus deformities exceeding $20^{\circ} .^{13}$ One neurovascular complication was observed in this series. The patient developed a drop foot due to a compartment syndrome two days after surgery. Fasciotomy was performed, and function was completely restored three months later. After this complication we discontinued the use of epidural analgesia for our lengthening osteotomies, as it can cause a delay in the diagnosis of a compartment syndrome. We would not recommend using epidural analgesia for this type of surgery unless compartment pressures are monitored.

Fixator-assisted correction of acute deformity and consecutive lengthening over an intramedullary nail can address two pathologies at the same time. Although the combination is technically more demanding than external fixation alone, it has the advantages of a shorter external fixation time, protection against fracture of the regenerated bone, and earlier rehabilitation. Fewer pin-track infections and compliance problems were observed, as well as increased patient comfort compared to use of the circular external fixator alone, owing to the shorter external fixator time and the use of fewer pins and wires.

No benefits in any form have been received or will be received from a commercial party related directly or indirectly to the subject of this article.

\section{References}

1. Herzenberg JE, Paley D. Tibial lengthening over nails (LON). Techniques in Orthopaedics 1997;12:250-9.

2. Paley D, Herzenberg JE, Bor N. Fixator-assisted nailing of femoral and tibial deformities. Techniques in Orthopaedics 1997;12:260-75.

3. Kocaoglu M, Eralp IL, Bilen FE, Balci HI. Fixator assisted acute femoral deformity correction and consecutive lengthening over an intramedullary nail. J Bone Joint Surg [Am]2009;91-A:152-9.

4. Paley D, Herzenberg JE, Tetsworth K, McKie J, Bhave A. Deformity planning for frontal and sagital plane corrective osteotomies. Orthop Clin North Am 1994;25:425-65.

5. Paley D, Tetsworth K. Mechanical axis deviation of the lower limbs: preoperative planning of multiapical frontal plane angular and bowing deformities of the femur and tibia. Clin Orthop 1992;280:65-71.

6. Paley D, Tetsworth K. Mechanical axis deviation of the lower limbs: preoperative planning of uniapical angular deformities of the tibia or femur. Clin Orthop 1992;280:48-64.

7. Donnan LT, Saleh M, Rigby AS. Acute correction of lower limb deformity and simultaneous lengthening with a monolateral fixator. J Bone Joint Surg [Br]2003;85-B:254-60.

8. Paley D, Herzenberg JE, Paremain G, Bhave A. Femoral lengthening over an intramedullary nail: a matched-case comparison with llizarov femoral lengthening. J Bone Joint Surg [Am] 1997;79-A:1464-80.

9. Paley D. Problems, obstacles, and complications of limb lengthening by the llizarov technique. Clin Orthop 1990;250:81-104

10. Tsuchiya H, lehara K, Abdel-Wanis ME, et al. Deformity correction followed by lengthening with the llizarov method. Clin Orthop 2002;402:176-83.

11. Kocaoglu M, Eralp L, Kilicoglu O, Burc H, Cakmak M. Complications encountered during lengthening over an intramedullary nail. J Bone Joint Surg [Am]2004;86A:2406-11.

12. Eralp L, Kocaoglu M, Cakmak M, Ozden VE. A correction of windswept deformity by fixator assisted nailing: a report of two cases. J Bone Joint Surg [Br] 2004;86B:1065-8.

13. Paley D. Principles of deformity correction. Berlin: Springer, 2002

14. Eralp L, Kocaoglu M, Yusof NM, Bulbul M. Distal tibial reconstruction with use of a circular external fixator and an intramedullary nail: the combined technique. J Bone Joint Surg [Am] 2007;89-A:2218-24.

15. Eralp L, Kocaoglu M. Distal tibial reconstruction with use of a circular external fixator and an intramedullary nail: surgical technique. J Bone Joint Surg [Am] 2008;90B (Suppl 2 Pt 2):181-94.

16. Park HW, Yang KH, Lee KS, et al. Tibial lengthening over an intramedullary nail with use of the llizarov external fixator for idiopathic short stature. J Bone Joint Surg [Am]2008;90-A:1970-8.

17. Watanabe K, Tsuchiya $\mathbf{H}$, Sakurakichi $\mathbf{K}$, et al. Tibial lengthening over an intramedullary nail. J Orthop Sci 2005;10:480-5

18. Baumgart R, Bürklein D, Hinterwimmer $S$, Thaller $P$, Mutschler $\mathbf{W}$. The management of leg-length discrepancy in Ollier's disease with a fully implantable lengthening nail. J Bone Joint Surg [Br] 2005;87-B:1000-4.

19. Wu CC, Chen WJ. Tibial lengthening: technique for speedy lengthening by external fixation and secondary internal fixation. J Trauma 2003;54:1159-65.

20. Rozbruch SR, Kleinmann D, Fragomen AT, Ilizarov S. Limb lengthening and then insertion of an intramedullary nail. Clin Orthop 2008;466:2923-32.

21. Clasper JC, Stapley SA, Bowley DMG, et al. Spread of infection, in an anima model, after intramedullary nailing of an infected external fixator pin tract. $J$ Orthop Res 2001;19:155-9.

22. Matsoukis J, Thomine JM, Khallouk R, Biga N. Secondary locked nailing of the leg after external fixation: 25 cases. Rev Chir Orthop Reparatrice Appar Mot 1991;77:555-61 (in French).

23. Kristiansen LP, Steen H. Lengthening of the tibia over an intramedullary nail, using the llizarov external fixator: major complications and slow consolidation in 9 lengthenings. Acta Orthop Scand 1999;70:271-4.

24. Nogueira MP, Paley D, Bhave A, et al. Nerve lesions associated with limb-lengthening J Bone Joint Surg [Am] 2003;85-A:1502-10. 